\title{
Biomass Balance: An Innovative and Complementary Method for Using Biomass as Feedstock in the Chemical Industry
}

\author{
Christian Krüger, Andreas Kicherer, Claudius Kormann \\ and Nikolaus Raupp
}

\begin{abstract}
Fossil resource and greenhouse gas savings can be claimed when certified biomass is co-fed with fossil raw materials into a highly efficient interlinked production network. BASF and partners have developed a novel biomass balance certification standard for chemical synthesis. It offers a reliable response to customers and end consumers who are increasingly interested in solutions that are based on renewable feedstock without compromising resource efficiency and performance. The new standard describes how renewable feedstock is attributed to a given sales product. Existing products can thus be derived from biomass and provided with third-party certification. Highest technical product standards can be maintained while fostering the strategic goals of a bio-economy, often requested from different stakeholders.
\end{abstract}

\section{BASF's Biomass Balance Approach}

The Circular Economy (CE) concept has gained a broad momentum in politics, industry, and society within the past few years [1]. One of the six levers is the shift to renewable energy and materials, which allow companies to reclaim, retain, and regenerate the health of ecosystems. For the chemical industry, it is still a big challenge to use renewable feedstocks. Bio-based chemistry is currently no solution to a rapid switch to renewable feedstocks because of fundamental limits. Only some products can be produced and large investments must be executed in R\&D and production assets. BASF found a concept to introduce biomass by using existing chemical pathways in a cost-efficient way. The sustainability of feedstocks and the mass balance between feedstocks and final products is proven by an independent certificate:

C. Krüger $(\bowtie) \cdot$ A. Kicherer · C. Kormann

BASF SE, Sustainability Strategy, 67056 Ludwigshafen, Germany

e-mail: christian.krueger@basf.com

N. Raupp

BASF SE, Global Sustainability Manager Dispersions \& Pigments,

67056 Ludwigshafen, Germany

(C) The Author(s) 2018

E. Benetto et al. (eds.), Designing Sustainable Technologies,

Products and Policies, https://doi.org/10.1007/978-3-319-66981-6_12 
This concept is called "The Biomass Balance Approach". This approach is applicable to almost all fossil-based products in the chemical industry (see Fig. 1, [2]).

Certified renewable feedstock (e.g. biogas derived from organic waste) replaces fossil resources at the beginning of the value chains in the chemical industry. Then the renewable feedstock is attributed verifiably to sales products in the corresponding quantities (see Fig. 2: comparison to bio-based chemistry). Third-party certification (TÜV SÜD) confirms to customers that BASF has used the required

Feedstock

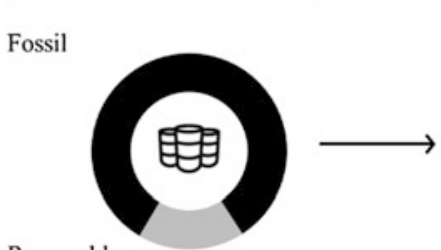

Renewable

Use of renewable feedstock in very first steps of chemical production (e.g. steam cracker)
BASF Production

\section{Verbund}

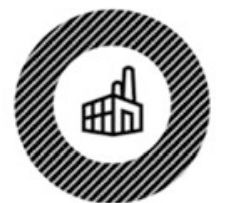

Utilization of existing Production Verbund for all production steps

\section{Products}

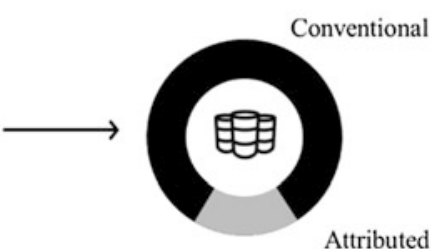

Attribution of renewable feedstock to selected products

Fig. 1 BASF's biomass balance approach

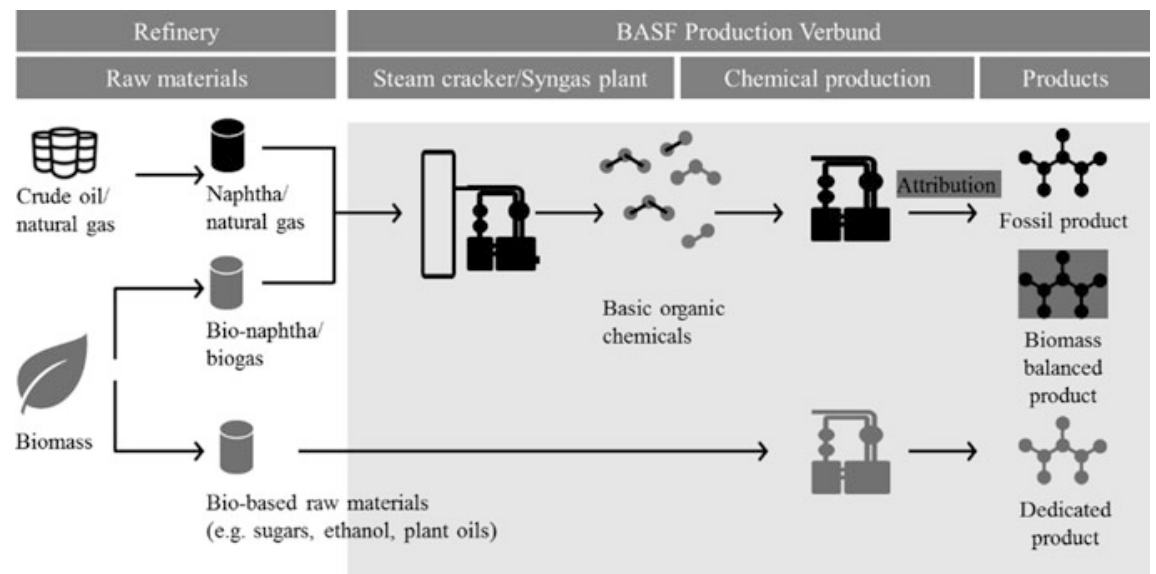

Fig. 2 Comparison of the biomass balance chain-of-custody method with dedicated production of bio-based materials 
quantities of renewable feedstock for the products they purchase [3]. The resulting products are called "Biomass balanced products". They are technically identical to their fossil comparatives but they are associated with quantifiably lower greenhouse gas (GHG) emissions due to the renewable feedstock used. The biomass balance chain-of-custody method is applicable to almost all products in BASF's portfolio, for example Acronal ${ }^{\circ}$ binders used for premium decorative paints. To date, more than 50 BASF products have already been certified, and several of them have been introduced into the market, thus contributing to sustainable development by saving fossil resources and reducing GHG emissions. BASF has received great attention thanks to the biomass balance method and has been selected as finalist for the "The Circulars 2017 Award" in the category "Multinational". The biomass balance method enables BASF to react quickly and flexibly to the increased interest to use renewable raw materials thus helping customers to differentiate in the market.

\section{Biomass Balance in Chemical Processes}

Comprehensive experience about mass balance methods is already available in other markets, especially in the biofuel, biogas and bioenergy markets [4]. Therefore, only minor adaptation to existing standards is needed for using BASF's biomass balance method in chemical production.

The system boundary is defined as the integrated chemical production system, which represents a physically interconnected arrangement of production sites at the same location, or the physical interconnection of operating facilities over different locations by means of dedicated transportation systems (e.g. pipelines, rolling pipelines).

Only sustainably sourced biomass or bio-based products are used to replace fossil comparatives to manufacture intermediates and final products. Bio-based renewable feedstock may strongly differ in value for a chemical synthesis. In order to make renewable feedstock of varying "chemical value" comparable to fossil feedstock, we introduced a correction factor for each raw material similar to the biofuel sector. BASF uses the lower heating value (LHV) as the most appropriate one. Therefore, each consignment of raw material entering the system boundary (i.e. the input) is assessed according to its LHV.

The exchange of fossil raw materials with bio-based feedstocks for production allows for new claims. For example, according to the TÜV SÜD standard [3] the following sales claim is certifiable for BASF and customers: "Fossil resource saving product. $100 \%$ of the fossil feedstock required for the manufacturing of this product was replaced in the production site by renewable raw materials."

Only renewable feedstock that enters in intermediates or products is eligible for the biomass balance chain-of-custody method. Raw materials needed for generating energy as steam or electricity are not counted. 


\section{Sustainability of Renewable Feedstocks}

Typically, renewable raw materials are usually not superior in all environmental categories and pros and cons have to be considered. Therefore, BASF only uses sustainable renewable feedstock, which is certified as sustainable according to the criteria of the Renewable Energy Directive of the EU Commission. Under this framework several standards (e.g. ISCC, REDcert) comply with principles such as:

(1) Sustainable production of feedstock

(2) Fulfilment of social standards in agriculture

(3) Protection of biodiversity

(4) Reduction of greenhouse gas emissions

(5) Minimized interference with local food supply

BASF strives to continuously improve the sustainability profile of purchased bio-based feedstocks and therefore it is important to keep the share of 1st generation renewables as low as possible. Thanks to new collections systems and innovative technologies, the production of renewable feedstocks based on wastes (e.g. kitchen or other residues) is getting more attractive, and BASF is cooperating with its suppliers to broaden the sustainable feedstock portfolio.

For the chemical industry, naphtha and natural gas are among the most important raw materials. BASF has identified certified bio-based comparatives without technical compromises. By replacing naphtha and natural gas at the beginning of the value chain at highly optimized Verbund sites, BASF can principally produce many thousands of biomass balance products, which can be used as drop-in solution for customers in various industries.

\section{Implementation in LCA}

Life Cycle Assessment (LCA) is an important tool to evaluate quantitatively the environmental impacts of products [5]. Therefore, BASF implemented the biomass balance concept into LCA by respecting the appropriate ISO 14040 series.

The calculation for BMB products is conducted in GaBi software on the basis of the existing model for the fossil-based product. A material flow analysis is used that enables calculating the feedstock use in the final product.

The respective BMB product is calculated on the basis of the fossil product by replacing fossil-based naphtha and natural gas with biofeedstock derived naphtha (= bionaphtha) and biofeedstock derived natural gas (= biogas). In Fig. 3 the calculation principle of the environmental burden B for biomass balance products is shown, which is the sum of the difference of the bio-based feedstocks and its fossil comparatives. 


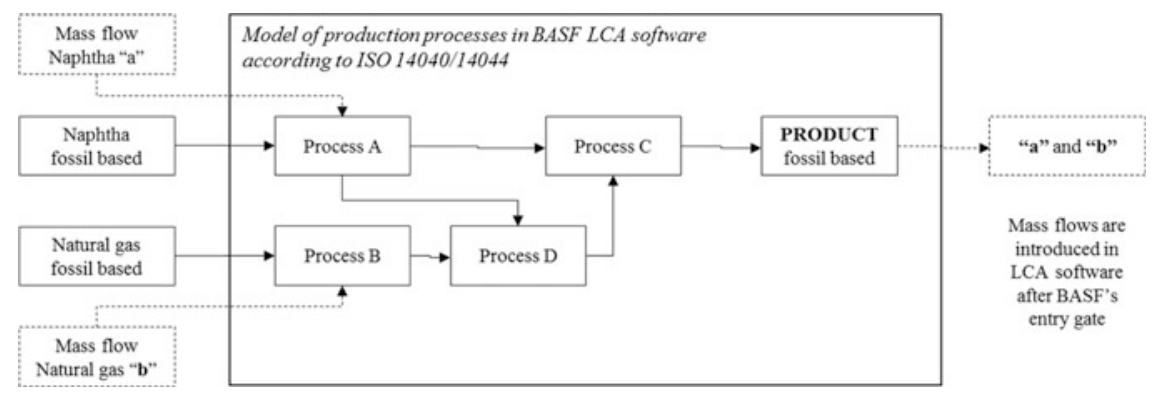

Fig. 3 Biomass balance calculation principle (example: bionaphtha and biogas)

The calculation of the life cycle inventory for BMB products is according to the equation as shown below:

$$
\mathrm{B}=\mathrm{B}_{\text {fossil }}+\mathrm{a} \times\left(\mathrm{cv}_{\mathrm{BN} / \mathrm{N}} \times \mathrm{B}_{\mathrm{BN}}-\mathrm{B}_{\mathrm{N}}\right)+\mathrm{b} \times\left(\mathrm{cv}_{\mathrm{BG} / \mathrm{NG}} \times \mathrm{B}_{\mathrm{BG}}-\mathrm{B}_{\mathrm{NG}}\right)
$$

where:

$\mathrm{B}, \mathrm{B}_{\text {fossil }}, \mathrm{B}_{\mathrm{BN}}, \mathrm{B}_{\mathrm{BG}}, \mathrm{B}_{\mathrm{N}}, \mathrm{B}_{\mathrm{NG}}$ : environmental burdens

a: amount of naphtha substituted by bionaphtha

b: amount of natural gas substituted by biogas

cv: "chemical value" factor (dimensionless): $\mathrm{cv}=\mathrm{LHV}_{\text {fossil feedstock (substituted) }}$ / $\mathrm{LHV}_{\text {biofeedstock }}$

LHV: lower heating value

Indices: $\mathrm{BN}=$ bionaphtha, $\mathrm{N}=$ naphtha, $\mathrm{BG}=$ biogas, $\mathrm{NG}=$ natural gas

\subsection{Chemical Value Factor (cv)}

Fossil feedstocks cannot always be replaced equally on a mass basis by bio-based comparatives, because of its different chemical nature in many cases. Sometimes bio-based feedstocks are used instead of fossil, where the carbon content is similar, but the energetic value is lower. Therefore, it is necessary to consider the "chemical value" of feedstock (the term coined by BASF in the context of the BMB approach, although it is not necessarily related to chemical parameters but is used to denote the use of feedstocks as chemicals rather than energy sources). The main feedstocks in the chemical industry are naphtha and natural gas, which are further processed either by cracking or oxidation, which takes place at high temperatures. The calorific value of those feedstocks can be used as an approximation of the chemical value, assuming lower heating value (LHV). The latter is also the determining factor for the design of the plant. 


\section{Conclusions}

BASF's biomass balance is an innovative approach to introduce biomass to the chemical industry, which is certified by an independent party. We believe that it is complementary to bio-based chemistry to further increase the consumption of renewable materials as feedstock for the chemical industry. Our customers acknowledge two main advantages:

(1) The customer can use a biomass balanced product as drop-in solution without any compromise in performance. For most existing fossil-based products we can provide biomass balanced alternatives by introducing sustainably sourced bionaphtha and biogas into our interconnected production sites.

(2) There is no need for investment into $R \& D$ and new assets (which will usually make new products more expensive).

A certification standard from TÜV SÜD requires the sustainability of the renewable feedstocks and its correct use for the production of biomass balanced products. BASF is able to easily calculate LCAs without building up the whole value chains separately from the fossil route in a LCA model by respecting existing ISO standards.

\section{References}

1. Peter Lacy et al., Waste to Wealth: The Circular Economy Advantage, Palgrave, 2015.

2. <https://www.basf.com/en/company/sustainability/environment/resources-and-ecosystems/ renewable-raw-materials/biomass-balance.html> BASF's biomass balance approach, website from BASF (Accessed DD:05.2017).

3. <http://www.tuev-sued.de/plants-buildings-technical-facilities/focal-topics/renewable-energies/ renewable-resources> Renewable Resources, website from TÜV SÜD (Accessed DD.05.2017).

4. <http://www.ble.de/SharedDocs/Downloads/DE/Klima-Energie/Nachhaltige-Biomasseherstellung/ LeitfadenNachhaltigeBiomasseherstellung.html?nn=8911410> Leitfaden Nachhaltige Biomasseherstellung, BLE 2010, Website from German Federal Office for Agriculture and Food (Accessed DD.05.2017).

5. Peter Saling, The BASF Eco-Efficiency Analysis-A 20-year success story, BASF, 2016. 
Open Access This chapter is licensed under the terms of the Creative Commons Attribution 4.0 International License (http://creativecommons.org/licenses/by/4.0/), which permits use, sharing, adaptation, distribution and reproduction in any medium or format, as long as you give appropriate credit to the original author(s) and the source, provide a link to the Creative Commons license and indicate if changes were made.

The images or other third party material in this chapter are included in the chapter's Creative Commons license, unless indicated otherwise in a credit line to the material. If material is not included in the chapter's Creative Commons license and your intended use is not permitted by statutory regulation or exceeds the permitted use, you will need to obtain permission directly from the copyright holder.

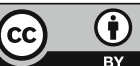

